\title{
Educação em saúde para portadores de doença mental: relato de experiência*
}

\author{
HEALTH EDUCATION FOR THE MENTALLY ILL: A FIRST-HAND ACCOUNT
}

EDUCACIÓN EN SALUD PARA PORTADORES DE ENFERMEDAD MENTAL: RELATO DE EXPERIENCIA

\author{
Vanessa Romeiro Ruiz¹, Alessandra Ribeiro Lima², Ana Lúcia Machado ${ }^{3}$
}

\section{RESUMO}

A experiência descrita no presente texto refere-se a um projeto efetivo de educação em saúde num ambulatório de Saúde Mental em São Paulo, realizado por discentes de Enfermagem. A crença na conquista da cidadania pelo doente mental e a compreensão de que a educação pode tornar-se um dos instrumentos de emancipação dos sujeitos, foram os pressupostos do projeto. Houve uma fase curta e outra prolongada, ocorrendo no formato de grupo semanal aberto a usuários e familiares, com caráter participativo onde todos tinham liberdade, pois o espaço era aberto a discussões com trocas de opinião e experiências. As temáticas abordadas foram referentes às doenças crônicas, destacando dentre estas os transtornos mentais, transmissíveis e crônicodegenerativas.

\section{PALAVRAS-CHAVE}

Enfermagem.

Saúde mental.

Educação em saúde.

\begin{abstract}
The account in this text refers to an effective health education project in a Mental Health post in Sao Paulo for which nursing department students are responsible. The belief in the mentally ill person conquering rights as citizens as well as understanding that the education may become the individual's most valuable emancipation tools were the starting point of the project. There was a short phase as well as a long one, both of which occurred in the weekly open group format to users and their family members, and whose characteristics were free participation, since the space was open for discussion and the exchange of both opinions and experiences. The themes were chronic illnesses, and those highlighted ones were mental illnesses, communicable diseases and chronic degenerative-illnesses.
\end{abstract}

\section{KEYWORDS}

Nursing.

Mental Health.

Health Education.

\section{RESUMEN}

El presente texto trata sobre un proyecto efectivo de educación en salud em consultorio externo de Salud Mental en São Paulo, realizado por discentes de Enfermería. La creencia en la conquista de la ciudadanía por el enfermo mental y la comprensión de que la educación puede tornarse uno de los instrumentos de emancipación de los sujetos, fueron los presupuestos del proyecto. Hubo una fase corta y otra prolongada, ocurriendo bajo la forma de grupo semanal abierto a usuarios y familiares, con carácter participativo donde todos tenían libertad, pues el espacio era abierto a discusiones con intercambios de opinión y experiencias. Las temáticas abordadas fueron referentes a las enfermedades crónicas, destacando entre éstas los trastornos mentales, transmisibles y crónico degenerativas.

\section{PALABRAS CLAVE}

Enfermería.

Salud Mental.

Educación en Salud
* Projeto desenvolvido pelo programa BolsaTrabalho da Coordenadoria de Assistência Social (COSEAS)para alunos de graduação da Universidade de São Paulo. Trabalho apresentado no formato poster no $53^{\circ}$ Congresso Brasileiro de Enfermagem, em Curitiba, outubro de 2001.

1 Enfermeira, formada pela Escola de Enfermagem da Universidade de São Paulo (EEUSP).

2 Enfermeira, formada pela EEUSP.

3 Professora Doutora do Departamento de Enfermagem Materno-Infantil e Psiquiátrica da EEUSP.

almachad@usp.br

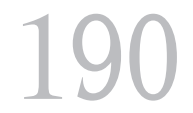




\section{INTRODUÇÃO}

O Brasil, nas últimas décadas, vem sofrendo um complexo processo de transição epidemiológica, havendo uma tendência à redução da mortalidade geral e da mortalidade infantil, assim como o aumento da expectativa de vida e conseqüente elevação da participação dos idosos na composição demográfica. Em decorrência desse quadro, houve um aumento de mortes por doenças crônico-degenerativas $\mathrm{e}$, devido às desigualdades regionais existentes em nosso território e suas precárias condições sanitárias, há o ressurgimento de várias doenças infecto-contagiosas ${ }^{(1)}$.

Sabendo que as doenças crônicas, destacando dentre estas os transtornos mentais e as crônico-degenerativas, requerem um tratamento poli-medicamentoso, dependente de tecnologias e acompanhamento constante por especialistas sendo, portanto, um tratamento oneroso, e que as doenças infectocontagiosas são passíveis de prevenção, surge a necessidade de se fazer educação em saúde, sendo este um instrumento para a promoção da saúde ${ }^{(1)}$.

Este trabalho não pretende discutir a questão epidemiológica em si, os escritos acima sinalizam o quadro mais amplo das condições de saúde da população brasileira.

Utilizamos esta definição de educação em saúde:

quaisquer combinações de experiências de aprendizagem delineadas com vistas a facilitar ações voluntárias conducentes à saúde,

e promoção em saúde:

combinação de apoios educacionais e ambientais que visam a atingir ações e condições de vida conducentes à saúde ${ }^{(2)}$.

O processo educativo tem a finalidade de transmitir informações para a população, objetivando a conscientização a respeito dos agravos à saúde. No entanto, isto só irá acontecer se a pessoa que receber a informação ver isto como importante para si.

Os processos educativos envolvem uma comunicação bilateral ou seguem uma comunicação que envolve o educador e o educando, um processo dialógico, para o qual ambos contribuem, cada qual à sua maneira para a construção do conhecimento. Tais proces- sos ocorrem com base no contexto de vida das pessoas, dos seus cotidianos, das suas experiências e devem ter como propósito libertar as pessoas para que estas possam ser sujeitos sociais capazes de fazer opções construtivas para suas vidas e para a sociedade.

A educação em saúde é um trabalho dirigido para atuar sobre o conhecimento das pessoas, para que elas desenvolvam juízo, crítica e capacidade de intervenção sobre suas vidas e sobre o ambiente com o qual interagem e, assim, criarem condições para se apropriarem de sua própria existência.

A educação em saúde por si só, não tem como arcar com a responsabilidade de promover a saúde, pois para se ter saúde não basta a resolução de problemas biológicos. É necessário que haja integração de ações intersetoriais, tentando solucionar as necessidades sociais, econômicas, políticas, culturais e religiosas, visto que todos estes setores interferem na saúde das pessoas.

Acreditamos que diretrizes do SUS e da Reforma Psiquiátrica, compõem um conjunto de políticas públicas direcionadas à efetivação de direitos, acessos, redes de atenção diversificadas e o resgate da cidadania dos sujeitos. Faremos, então, um breve comentário a este respeito.

Para a efetiva implantação do Sistema Único de Saúde (SUS) em nosso país, é imprescindível "uma política em defesa da vida" e esta deve estar "intimamente articulada à problemática do exercício da cidadania"(3).

Assim sendo, ao se pensar na consciência sanitária e na relação do usuário com o serviço de saúde, concordamos com diretrizes que visem a

\section{organização de um processo de trabalho em saúde, nas instituições, que incorpo- ra as amplas dimensões das questões referentes aos problemas (de saúde)(3).}

No tema relação instituição-usuário, pensando na humanização, é preciso "garantir acesso à informação desde o ponto de vista individual até o coletivo"(3). Pensando na consciência sanitária, é fundamental

contribuir para a "elevação" da consciência sanitária das pessoas e grupos organizados da sociedade em relação à: saúde como direito e em defesa da vida;
Educação em saúde para portadores de doença mental: relato de experiência 
Vanessa Romeiro Ruiz Alessandra Ribeiro Lima Ana Lúcia Machado estabelecer uma relação pedagógica crítica, pois a população também sabe, para tratar as relações: problemas de saúde/ causas sociais/serviços/direitos ${ }^{(3)}$.

Acreditando no exposto acima e imbuídas dos princípios da Reforma Psiquiátrica e da Reabilitação Psicossocial, elaboramos um projeto de educação em saúde destinado à população que freqüenta o ambulatório de Saúde Mental do Mandaqui, na cidade de São Paulo. A proposta diz respeito à educação em saúde, ou seja, a constituição de um grupo aberto onde possam ser discutidas questões sobre a saúde em geral dos usuários deste Ambulatório. O que sustenta a idéia é a crença na conquista da cidadania pelo doente mental, fato este que passa obrigatoriamente pelo direito à informação.

\section{OCENÁRIO}

As instituições extra-hospitalares em saúde mental, como o Ambulatório de Saúde Mental do Mandaqui, geralmente seguem as diretrizes da Reforma Psiquiátrica, ou seja, priorizar o atendimento ao doente mental em locais onde seja possível a reconstrução da cidadania destes sujeitos. Estas instituições devem contar com um número adequado de profissionais de formação variada, capacitados e qualificados para a intervenção reabilitatória, com projetos terapêuticos reais e possíveis, tendo necessariamente o sujeito como objeto das ações de cuidado e não a doença $a^{(4,5)}$.

O Ambulatório em questão, segue os princípios da Reabilitação Psicossocial, quais sejam:

\begin{abstract}
O incremento da consciência do paciente a respeito dos seus problemas: pessoais, familiares, de trabalho, econômicos, sociais, culturais; o incremento da autonomia afetiva-material-social do paciente; e o incremento da incorporação do paciente na vida de relação social e política(6).
\end{abstract}

Este Equipamento que antes pertencia ao Estado, está vinculado à Secretaria Municipal da Saúde de São Paulo desde junho de 2001. As diretrizes organizacionais do serviço seguem a Portaria do Ministério da Saúde de $\mathrm{n}^{\circ} 224$ de $1992^{(7)}$ e outros regimentos estaduais. O Ambulatório de Saúde Mental do Mandaqui, constitui-se em um serviço especializado que oferece à população possuidora de transtornos mentais uma proposta de atendimento na qual prevalece o respeito à dignidade do usuário e família. Há responsabilidade por parte dos profissionais com o aprimo- ramento, tanto técnico quanto ético, com a construção de um projeto terapêutico individualizado para os doentes mentais assistidos que vislumbre a autonomia desses sujeitos, bem como a reinserção social e familiar.

Contando sucintamente a história deste Ambulatório, o ano de 1976 marca o início de suas atividades. Hoje, possui planta física básica, com vários consultórios, recepção e serviço administrativo. A assistência organiza-se com base em plantões técnicos, consultas individuais com psiquiatras e psicólogos, além de atendimentos em grupo, incluindo aí a presença de membros da equipe de enfermagem, assistentes sociais e terapeutas ocupacionais. Os grupos atendem a usuários psicóticos $\mathrm{e}$ neuróticos. As atividades são planejadas em grupos de leitura, cozinha, horta, jardinagem, cuidados pessoais, artesanato, vídeo, esporte, jogos, festas, atividades artísticas, terapia ocupacional, expressão verbal e corporal, atividades livres e clínicas. A proposta de atendimento faculta ao usuário comparecer ao serviço em determinados dias, portanto ele não permanece de forma integral no mesmo ${ }^{(8)}$.

\section{O PROJETO - HISTÓRICO DE SUA FORMAÇÃO}

Ao planejar as atividades dos alunos de graduação em Enfermagem da Escola de Enfermagem da USP, para o ensino teórico-prático (estágio) da disciplina Enfermagem em Saúde Mental e Psiquiátrica no ambulatório de Saúde Mental do Mandaqui, para o período de maio/junho de 1999, surgiu a idéia de estruturar um grupo onde os alunos atuassem de forma mais específica e que atendesse a uma demanda de informação dos usuários.

Esta idéia foi planejada com a diretora, enfermeira, profissional responsável pelo ensino na instituição, técnico do Núcleo de Ensino e Pesquisa da Região IV e docente.

A proposta dizia respeito à educação em saúde, ou seja, um grupo aberto onde pudessem ser discutidas questões sobre a saúde em geral dos usuários, privilegiando informações sobre doenças transmissíveis. Inicialmente, teve a denominação de Grupo Temático, Grupo Informativo ou Grupo de Sala de Espera, ficando posteriormente intitulado como Grupo de Educação em Saúde. Alguns temas foram elencados com base em pedidos feitos pelos próprios usuários ou da necessidade sentida pelos profissionais. 
Decidimos então, que ao iniciar o estágio, os alunos desenvolveriam esta atividade às quintas-feiras, das $9 \mathrm{~h} 30$ às $10 \mathrm{~h} 30$, na sala de estar dos usuários. O primeiro tema seria escolhido por nós, sendo que os próximos temas seriam definidos a partir da escuta aos usuários durante o grupo.

Assim foram realizados no período de maio/junho e agosto/setembro de 1999, grupos cujas temáticas e freqüência serão descritas a seguir. Esclarecemos que o número total inclui usuários, familiares, acompanhantes e, às vezes, funcionários. Nos meses de maio/ junho:

- Tuberculose = 4 participantes;

- AIDS = 10 participantes;

- Dengue $=7$ participantes;

- Aids $=20$ participantes;

- Hipertensão = 11 participantes.

Nos meses de agosto/setembro:

- AIDS = 13 participantes;

-Transtornos clínicos decorrentes do alcoolismo $=5$ participantes;

- Tabagismo = 12 participantes;

- Hipertensão = 9 participantes;

- Efeitos colaterais dos psicofármacos $=22$ participantes.

Os alunos preparavam previamente o material ilustrativo no formato de álbum seriado, contendo ilustrações e informações numa linguagem clara, direta e objetiva. Utilizaram também filmes educativos e dinâmicas de exercícios e estimulação. Foram feitas explanações e estabelecido um espaço aberto no sentido grupal, com todos sentados em círculo, estimulando maior participação dos usuários e familiares.

Alguns grupos exigiram ações específicas como por exemplo, ao final do grupo sobre Hipertensão, foi verificada a pressão arterial de todos os participantes, com as devidas orientações que se fizeram necessárias; ao final do grupo sobre AIDS, foi demonstrado o uso correto da camisinha. Durante o grupo sobre Tabagismo, foram feitas orientações sobre exercícios físicos e respiratórios e solicitada a participação dos presentes, com muito boa receptividade.

Em relação à divulgação, foram distribuídos cartazes pelo ambulatório convidando usuários e familiares a comparecer ao grupo.
O segundo grupo de alunos inovou ao preparar e distribuir pequenos convites entregues nos grupos, na sala de espera e deixados no balcão de recepção, o que provocou um estímulo maior para a participação dos usuários e familiares. Houve uma solicitação aos profissionais para que estimulassem a participação dos usuários durante as atividades grupais ao longo da semana.

Os usuários e acompanhantes/familiares que aguardavam consultas e o início de atividades grupais na sala de espera do ambulatório eram convidados a participar do grupo. Contou-se com a colaboração dos funcionários da recepção, tanto no sentido da divulgação do grupo, como estímulo aos pacientes e orientação aos demais membros da equipe sobre onde estavam os pacientes, caso fossem chamados para as atividades. Os usuários sugeriam temas para os grupos seguintes, ao longo da exposição temática do dia.

Um dos objetivos do ensino teórico-prático (estágio) dos alunos de graduação em Enfermagem ao cursarem a disciplina Enfermagem em Saúde Mental e Psiquiátrica é: contribuir para a formação do enfermeiro de modo a capacitá-lo a prestar assistência à pessoa na manutenção e recuperação de sua saúde mental.

Associado a este objetivo e acreditando que a reconquista da cidadania do doente mental passa obrigatoriamente pelo direito à informação, a concretização deste grupo é uma forma de assistência pautada na atitude reabilitatória sendo construída pelos profissionais de saúde mental.

Descrevendo rapidamente uma perspectiva avaliativa dos grupos de educação em saúde no referido ambulatório, podemos dizer que os mesmos ocorreram de forma dinâmica, com visível atenção dos participantes e empenho por parte dos alunos. A freqüência e o interesse dos usuários em participar dos grupos foram crescendo. A divulgação precisou ser ampliada tanto com os usuários, como com os profissionais. Concluímos, juntamente com alunos, profissionais e funcionários do ambulatório e, principalmente, com os usuários, familiares e acompanhantes que este grupo deve permanecer em constante organização e dinamicidade, passando a fazer parte da cultura assistencial-reabilitatória do ambulatório.
Educação em saúde para portadores de doença mental: relato de experiência 
Vanessa Romeiro Ruiz Alessandra Ribeiro Lima Ana Lúcia Machado

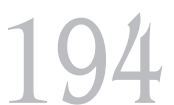

Rev Esc Enferm USP 2004; 38(2):190-6.
Com base nessa avaliação e num estudo que

aponta a necessidade de transformações nas ações educativas desenvolvidas nas unidades básicas vislumbrando que a educação torne-se um dos instrumentos de emancipação dos sujeitos ${ }^{(9)}$,

foi elaborado um projeto contínuo de educação em saúde, com a participação de duas graduandas em Enfermagem bolsistas, supervisão de uma docente, tendo a duração de um ano e seis meses, que será descrito a seguir.

\section{RELATO DE EXPERIÊNCIA}

Passaremos a descrever uma experiência prolongada do grupo de educação em saúde. A atividade esteve vinculada ao Projeto Bolsatrabalho da COSEAS (Coordena-doria de Assistência Social da USP), intitulado Cidadania do doente mental - o acesso às informações sobre saúde e doença no Ambulatório de Saúde Mental do Mandaqui, tendo como objetivos: possibilitar ao doente mental o acesso à informação sobre doenças transmissíveis, crônicas, doenças mentais e facilitar o entendimento e discussão sobre estas patologias.

Os grupos eram destinados aos usuários do serviço e a seus acompanhantes, sendo realizados em encontros semanais com duração de aproximadamente 1 hora, visando a disseminação de informações sobre saúde. Foi uma proposta educativa que resgatou noções básicas de atenção primária à saúde.

A estratégia pedagógica consistiu em breves exposições, utilizando-se de uma linguagem de fácil compreensão, com auxílio de recursos audiovisuais e de cartazes descritivos e ilustrativos que, facilitaram a apresentação, estimularam a participação, entendimento e a conscientização dos usuários. Acreditamos que com o auxílio destes recursos a porcentagem de informações incorporadas pelos sujeitos foi maior. $\mathrm{O}$ grupo teve caráter participativo, onde todos tiveram liberdade para interromper a apresentação caso houvesse dúvida, além disso, o espaço era aberto à discussões, onde os participantes expunham suas opiniões e trocavam experiências. Ao final foram fornecidos panfletos explicativos.

Para que os grupos pudessem ser realizados foi necessário primeiramente um planejamento das atividades.

A primeira etapa consistiu em selecionar temas; o critério utilizado foi o de escolher temas que abordassem doenças que pudessem ser prevenidas, ou pelo menos detectadas precocemente para um tratamento eficaz, como as doenças infecto-contagiosas (tuberculose, doenças sexualmente transmissíveis, dentre outras), saúde da mulher (câncer de mama e de colo uterino) e doenças crônico degenerativas (hipertensão arterial, diabetes, etc.) e doenças mentais, visando esclarecer usuários e familiares quanto a estas, buscando dessa forma facilitar o convívio familiar e a compreensão acerca dos processos de adoecimento.

Na segunda etapa foi realizado um levantamento de audiovisuais existentes na biblioteca da Escola de Enfermagem da USP. Selecionamos vídeos que tivessem no máximo 30 minutos de duração. A partir desta listagem, começamos a escolher os vídeos que mais interessavam, para que pudéssemos assistir e decidir se estes estariam de acordo com os nossos objetivos. Dentre os 5 vídeos escolhidos, apenas 1 foi selecionado para ser utilizado no grupo: "Doenças venéreas: plano de ataque" aborda o tema mostrando a forma de transmissão, os sintomas e as formas de prevenção da sífilis e da gonorréia, tudo isso na forma de desenho animado.

Na terceira etapa foi definida a fonte bibliográfica que serviria de base para as apresentações. Optamos principalmente pela busca de sites na internet por ser um recurso rápido e atual. Estas informações eram complementadas em livros, artigos e panfletos destinados ao público. O critério para a escolha destes materiais foi a abordagem do tema em linguagem simples e ampla. Sempre recorríamos a leitura de livros técnicos, os quais forneciam informações aprofundadas para que pudéssemos solucionar as dúvidas levantadas. Além disso, fizemos o levantamento de materiais ilustrativos já produzidos por agências ou órgãos de promoção à saúde.

$\mathrm{Na}$ quarta etapa fizemos uma listagem dos recursos materiais necessários, para a produção dos cartazes que auxiliam na apresentação e também para a divulgação dos grupos. Optamos por materiais simples, como papel pardo, canetas piloto e cola. Utilizamos a sala de informática da Escola de Enfermagem da USP para a impressão dos convites, cartazes, panfletos e ilustrações.

A divulgação das atividades foi feita oralmente ao final dos grupos, quando também solicitamos sugestões de novos assuntos. Distribuímos convites e afixamos cartazes pelo ambulatório com uma semana de antecedência. Profis- 
sionais e funcionários do ambulatório também ajudavam, divulgando nos grupos terapêuticos.

Os grupos ocorreram entre setembro de 2000 e março de 2002, com uma média de 12 participantes incluindo usuários e familiares, geralmente às sextas-feiras, às $14 \mathrm{~h}$.

Alguns temas abordados foram: hipertensão arterial, dengue, diabetes, câncer de mama, câncer de próstata, tuberculose, doenças sexualmente transmissíveis, esquizofrenia, anemia, transtorno bipolar, gripe, síndrome do pânico, atendimento em urgências, dentre outros.

Após tudo preparado para o primeiro grupo, era só aguardar o grande momento! Estávamos ansiosas, pois não sabíamos como seria a reação dos usuários já que as atividades de educação em saúde no ambulatório eram irregulares e tinham sido interrompidas. Estávamos preocupadas, pois não sabíamos se as pessoas iriam participar ou se recusar, se elas iriam se interessar pelo tema e se nós conseguiríamos passar as informações de forma clara. Gostaríamos que as pessoas se sentissem à vontade para fazer perguntas e tirar dúvidas, no entanto, não sabíamos como elas iriam se comportar, e já nos preparamos para não desanimar caso ficassem apáticas frente à apresentação.

Quando chegamos ao ambulatório havia algumas pessoas esperando para participar do grupo sobre hipertensão arterial, anteriormente divulgado. Funcionários do ambulatório disseram que estas já estavam perguntando por nós. Fomos então convidar os que estavam na sala de espera para que viessem participar do grupo; não havia muitas pessoas e no geral elas aceitaram o convite. Notamos que o interesse aumentou quando dissemos que no final iríamos verificar a pressão arterial dos interessados. Tanto funcionários quanto usuários e acompanhantes mostraram-se bastante receptivos, o que nos proporcionou segurança e tranqüilidade na apresentação. Conforme o prometido, começamos a verificar a pressão arterial das pessoas que haviam participado. Usuários que faziam parte de outros grupos terapêuticos do ambulatório viram o que estávamos fazendo, já que a sala que utilizávamos para a palestra não tinha porta. Estes usuários então, largaram suas atividades e vieram em massa para que pudéssemos verificar a pressão arterial. $\mathrm{O}$ ambiente ficou um pouco tumultuado, teve até usuário tocando berrante, e a auxiliar de enfermagem pegou outro esfigmomanômetro para nos ajudar.

Ao longo das nossas atividades no grupo de educação em saúde, sentimos que houve aperfeiçoamento dos conteúdos e dos recursos materiais utilizados, além de adquirirmos melhor entrosamento com os participantes.

Sempre quando terminávamos um grupo, era perguntado aos participantes se as informações tinham sido transmitidas de forma clara e se havia alguma dúvida. Freqüentemente eles faziam perguntas, às quais tentávamos responder da melhor forma possível, mesmo que a resposta fosse “não sabemos!". Nestes casos, nos comprometíamos a pesquisar e levar a resposta na semana seguinte, desde que a pessoa também se comprometesse em comparecer para recebê-la. De modo geral, as pessoas que participavam dos grupos diziam-se satisfeitas considerando a atividade importante, pois estavam aprendendo sobre as doenças, o que são e como prevení-las. Alguns participantes inclusive anotavam as informações e discussões para depois transmitir a outras pessoas. Durante os grupos sempre surgiam discussões relacionadas ao tema, e freqüentemente os participantes expunham suas experiências e dificuldades, neste momento era muito interessante o que acontecia, pois tentavam ajudar uns aos outros, dando conselhos, sugerindo alternativas, e o melhor de tudo é que muitas vezes ficava evidente que a pessoa que solicitava esclarecimentos, tinha sido realmente ajudada.

No grupo sobre diabetes pudemos perceber que dentre as pessoas que eram submetidas ao tratamento com insulina, havia a desinformação quanto a importância emrodiziarolocal daaplicaçãodamesma.

O tema câncer de mama contou com a participação de uma mulher que tinha sido submetida a quadrantectomia, relatando sua experiência aos demais: referiu ter notado o surgimento de um nódulo doloroso na região axilar, mas que ocultou esta informação do médico por achar irrelevante.

No tema câncer de próstata, houve a presença de dois homens que realizaram o exame de toque retal e contaram suas experiências, procurando estimular aos demais participantes a fazerem o exame e desmistificar o preconceito existente. As mulheres presentes estavam interessadas porque diziam que iam passar os dados para maridos e filhos. Houve dúvida se a próstata é um órgão exclusivamente masculino, muitos presentes não sabiam exatamente o que era a próstata e qual a sua função.

Ao longo dos grupos, pudemos observar que o número de participantes diminuiu. Questionamos as pessoas o porquê do não comparecimento e pudemos constatar que nossa estratégia de divulgação não estava proporcionando o impacto que esperávamos. Primeiramente, a aparência dos cartazes era
Educação em saúde para portadores de doença mental: relato de experiência 
Vanessa Romeiro Ruiz Alessandra Ribeiro Lima Ana Lúcia Machado

sempre a mesma, além disso o mural do ambulatório já apresenta uma poluição visual. Ambos fizeram com que a divulgação passasse desapercebida. Diante desse fato, nos reunimos e fizemos cartazes chamativos, com cores fortes, frases estimulantes e desenhos. O que percebemos posteriormente, é que esses cartazes corresponderam à nossa expectativa, porém essas mudanças devem ser constantes estimulando a presença dos usuários e acompanhantes.

\section{REFLEXÕES FINAIS}

A compreensão das condições de adoecimento e de seu caráter complexo, requer do profissional de saúde o ato de compartilhar saberes e representações com os clientes, acerca destas condições e das práticas de saúde. Acreditamos que,

faz-se necessário um saber mais sistemati-
zado sobre educação em saúde, vislumbran-
do práticas que incluam o cidadão no pro-
cesso enquanto ator social, reflexivo e
instrumentalizado com seu saber, para con-
tribuir no processo de mudança social( ${ }^{(9)}$.

A atividade descrita neste texto foi desenvolvida por discentes e docente de Enfermagem e esteve vinculada ao Projeto Bolsa-trabalho da USP, intitulado Cidadania do doente mental - o acesso às informações sobre saúde e doença no Ambulatório de

\section{REFERÊNCIAS}

(1) Buss PM. Promoção e educação em saúde no âmbito da Escola de Governo em Saúde da Escola Nacional de Saúde Pública. Cad Saúde Pública. 1999; 15(sup 2):177-85.

(2) Candeias NMF. Conceitos de educação e de promoção em saúde: mudanças individuais e mudanças organizacionais. Rev Saúde Pública 1997; 31(2):209-13.

(3) Merhy EE. Ineficiência do setor público. Saúde debate 1992; 35:46-50.

(4) Bezzerra Junior B, Amarante P. Psiquiatria sem hospício: contribuições ao estudo da reforma psiquiátrica. Rio de Janeiro: Relume/ Abrasco; 1992.

(5) Amarante P. Manicômio e loucura no final do século e do milênio. In: Fernandes MIA, organizador. Fim de século: ainda manicômios? São Paulo: Instituto de Psicologia da USP; 1999. p. 47-53.

(6) Saraceno B, Asioli F, Tognoni G. Manual de saúde mental: guia básico para atenção primária. São Paulo: Hucitec; 1994.
Saúde Mental do Mandaqui. O projeto teve como objetivos: possibilitar ao doente mental o acesso à informação sobre doenças transmissíveis, crônicas, doenças mentais e facilitar o entendimento e discussão sobre estas patologias. Para atingir tais objetivos, foram estruturados grupos no referido Ambulatório que tiveram caráter participativo. $\mathrm{O}$ espaço era aberto às discussões, onde os participantes expunham suas opiniões e trocavam experiências.

Esta atividade de educação em saúde num ambulatório de Saúde Mental em curta e longa duração, demonstrou a concre-tude de ampliação dos territórios de ação do enfermeiro, a prática de interrelacionar saberes (saberes populares, da saúde coletiva e saúde mental), de exercer a responsabilidade enquanto trabalhadores e aprendizes de trabalhadores em saúde com a construção da cidadania dos sujeitos sob cuidados e da premência da inclusão do doente mental nas ações gerais e específicas da saúde.

Como o Ambulatório em questão segue as diretrizes da Reforma Psiquiátrica e da Reabilitação Psicossocial, reproduzimos um escrito sobre esta última, cujas práticas são consideradas um

processo que facilita a oportunidade para indivíduos; melhorando competências e introduzindo mudanças ambientais para criar uma vida com a melhor qualidade possível para pessoas que experimentaram uma desordem mental ${ }^{(10)}$.

(7) Brasil. Portaria MS n. 224, de 29 de janeiro de 1992. Estabelece diretrizes e normas para o atendimento ambulatorial. Conselho Regional de Psicologia. Trancar não é tratar: liberdade o melhor remédio, São Paulo, $2^{\mathrm{a}}$ ed. p. 42-8, 1997.

(8) Silva ALS, Machado AL. Reabilitação psicossocial: um desafio para a equipe multidisciplinar. In: Labate RC, organizador. Caminhando para a assistência integral. Ribeirão Preto: Scala; 1998. p. 131-44.

(9) Rosso CFW, Collet N. Os enfermeiros e a prática de educação em saúde em municípios do interior paranaense. Revista Eletrônica de Enfermagem[periódico online]Goiânia; 1999 out-dez. Disponível em: <http:// www.fen. ufg.br/revista $>$

(10) Hirdes A. Reabilitação psicossocial: dimensões teórico-práticas do processo. Erechim: EdiFAPES; 2001.
Rev Esc Enferm USP 2004; 38(2):190-6. 